\title{
The Impact of Snowball Earth Glaciation on Ocean Water $\delta^{18} \mathrm{O}$ Values
}

\author{
WiLliam F. DEFLIESE ${ }^{1}$ \\ ${ }^{1}$ School of Earth and Environmental Sciences, The University \\ of Queensland,w.defliese@uq.edu.au \\ It has been long recognized that glacial episodes can \\ affect the $\delta^{18} \mathrm{O}$ value of ocean water, where preferential \\ storage of ${ }^{16} \mathrm{O}$ in ice changes the ${ }^{18} \mathrm{O} /{ }^{16} \mathrm{O}$ ratio of the \\ ocean. The Snowball Earth glaciations of the \\ Cryogenian have the potential to cause very large \\ (perhaps permanent) changes in ocean water $\delta^{18} \mathrm{O}$ \\ values due to their increased ice volume and long \\ duration. Here, I use a numerical box model to \\ investigate ocean water $\delta^{18} \mathrm{O}$ values over the \\ Proterozoic and Phanerozoic. The model simulates \\ various temperature and tectonics dependant fluxes of \\ ${ }^{18} \mathrm{O}$, while also incorporating a zero-dimensional \\ climate model and ice volume component to model \\ glacial cycles. Monte Carlo simulations of the Sturtian \\ and Marinoan glaciations reveal that these had the \\ potential to alter ocean water $\delta^{18} \mathrm{O}$ values for hundreds \\ of millions of years after the termination of glaciation, \\ providing a mechanism for secular change in the $\delta^{18} \mathrm{O}$ \\ value of ocean water. This occurs as a very large \\ volume of ice (presumably, but not necessarily ${ }^{18} \mathrm{O}$ \\ depleted) is sequestered from the ocean, causing the \\ ocean to become enriched enough in ${ }^{18} \mathrm{O}$ for exchange \\ at mid-ocean ridges to remove ${ }^{18} \mathrm{O}$ from the ocean and \\ slowly change the overall ocean water $\delta^{18} \mathrm{O}$ value. \\ However, it is unlikely that the magnitude of this effect \\ is large enough to explain the secular trend in $\delta^{18} \mathrm{O}$ \\ value seen in compilations of Phanerozoic carbonates. \\ An additional finding of this work is that the duration of \\ the Sturtian glaciation required a very low $\mathrm{CO}_{2}$ \\ degassing rate on the order of $\sim 2 \mathrm{Tmol} /$ year, \\ significantly less than that estimated from riverine flux \\ or other mass balance approaches for the Phanerozoic.
}

